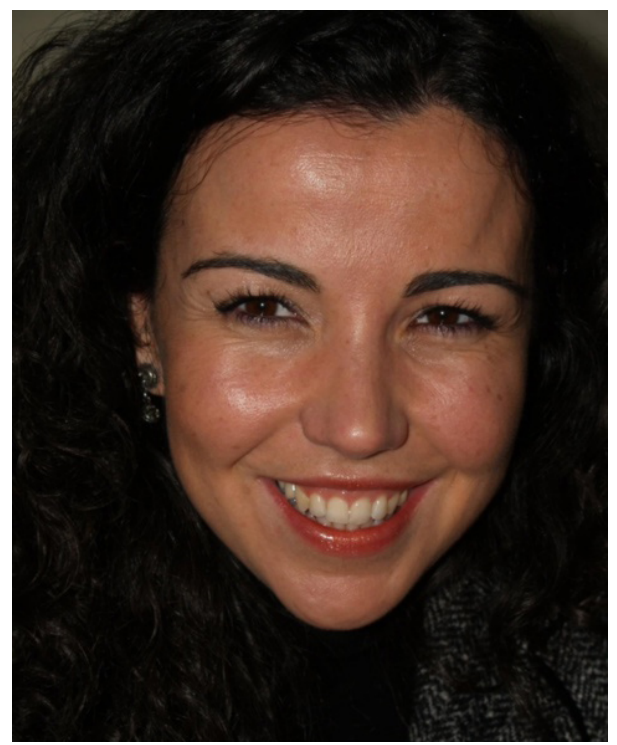

\title{
CUF Academic Center: Parceiro na Construção do Futuro
}

\section{CUF Academic Center: Partner in Building the Future}

\author{
Maria Barros ${ }^{1}$
}

Vivemos momentos desafiantes na nossa história, com incerteza sobre o futuro, mas, acredito, com vontade firme de pincelar o presente de esperança e de construir pontes seguras para o amanhã.

É neste ambiente, apelidado de VUCA (volatility, uncertainty, complexity \& ambiguity), que escrevo estas linhas que terminarão com a assinatura como Diretora da CUF Academic Center. Assino com muito orgulho e satisfação, mas igualmente com um enorme sentido de responsabilidade e sentido de missão, não só pelo legado que esta Academia transporta e encerra, mas também pela missão que tem a seu cargo e pelo espaço que pretende ocupar no panorama do ensino e da investigação nacional e europeia.

E é neste contexto, com a determinação alicerçada na cultura e valores CUF, como a inovação, o desenvolvimento humano e competência, que a CUF Academic Center pretende trilhar o seu caminho e ser um verdadeiro parceiro na construção do futuro.

A Academia transporta o ideal da educação que busca a conjugação de diferentes saberes e a sua aplicação, mas também a missão de aprofundar a investigação, criar (novos) saberes e expandir conhecimento.

Precisamente, a Gazeta Médica - pilar fundamental na divulgação do conhecimento e expressão científica da CUF dedicar-se-á na sua próxima edição a um tema alicerçante da educação em contexto do ensino e prática em saúde: a simulação.

A simulação, em contexto hospitalar, tem como objetivos a promoção da segurança do doente, a melhoria dos resultados clínicos e da experiência do cliente, aumentar a eficiência e consistência na operação, e, igualmente, captar, desenvolver e reter o talento humano.

A simulação é, hoje em dia, um instrumento fundamental e preferencial na garantia da segurança do doente e qualidade em saúde, suportado em literatura médica, constitui, igualmente, gold-standard internacional no treino e aperfeiçoamento de estudantes, profissionais e equipas de saúde e afirma-se como uma importante interface de inovação e colaboração em tecnologias de saúde.

E é esta a base da missão escolhida pelo Centro de Simulação Biomédica CUF: garantir a promoção da segurança do doente, a qualidade clínica, experiência irrepreensível do cliente e a formação contínua dos profissionais da CUF através 
da utilização de tecnologias de simulação, no quadro global da missão da própria Academia CUF.

Assim, a prática consistente, assistida, num ambiente controlado, que o Centro de Simulação permite e promove, é fundamental neste mundo tão volátil e complexo em que nos movemos. Tão bem aplicado aqui o ditado que afirma "que a prática leva à perfeição".

Igualmente estratégico para a CUF, e prioridade absoluta da CUF Academic Center, é a cooperação, a longo prazo, com parceiros para o desenvolvimento da atividade de prestação de cuidados de saúde de excelência, e o investimento contínuo no ensino pré- e pós-graduado assim como a cooperação com as instituições universitárias de maior relevância nacional. Entendemos que os movimentos de parceria e envolvimento com instituições de referência são fundamentais para a diferenciação técnica, a elevada qualidade dos cuidados prestados, assim como constituem fonte de inovação e desenvolvimento.

Neste contexto e neste âmbito, é mister referir um outro eixo estratégico da CUF Academic Center: a aposta na investigação. Assim, pretendemos desenvolver o Centro de Investigação que foi criado com o objetivo de desenvolver uma política pró-ativa de incentivo à investigação clínica e de projetos de investigação e translação. Esta atividade passa, em grande medida, pela captação de ensaios clínicos, fundamentais ao desenvolvimento e afirmação dos centros clínicos de excelência nas unidades CUF.

Para lá dos ensaios em parceria com a indústria, o centro de investigação pretende suportar o desenvolvimento da investigação interna, gerando conhecimento e contribuindo para o desenvolvimento da ciência, mantendo o seu apoio na atribuição das bolsas de doutoramento e outros programas de investigação, garantia da inovação e manutenção na vanguarda da prestação de cuidados de saúde.

Muitos são os projetos que a CUF Academic Center pretende prosseguir, dinamizar e desenvolver, com vista à diferenciação e humanização dos cuidados de saúde, num mundo em constante mudança, com a certeza de que a (boa) preparação permite antecipar desafios. Pretende, assim, a CUF Academic Center ser um verdadeiro parceiro na construção do futuro, alicerçado no ensino, investigação e humanização.

Maria Barros

Diretora da CUF Academic Center

"Não Te peço sapatos, peço-Te caminhos

O gosto dos caminhos recomeçados. Com as suas surpresas e as suas mudanças (...)" 